\title{
Research on the Relationship between Self-efficacy and Inquiry Community Model
}

\author{
https://doi.org/10.3991/ijet.v17i01.28547
}

\author{
Xiang Zhou
}

School of Foreign Languages, Hunan International Economics University, Changsha, China Graduate school of education, Stamford International University, Bangkok, Thailand

Zhoux2@hieu.edu.cn

\begin{abstract}
Online learning has the characteristics of large-scale, online and open implementation. It provides students with rich high-quality online learning resources and attracts a large number of learners. Exploring the teaching effect in the online and offline mixed environment has become a hot research topic. Thus, based on a comprehensive review of the literature on the interaction between self-efficacy and the exploratory community model, this paper establishes two models that affect cognitive existence. Using teaching existence and social existence, and taking self-efficacy as the intermediary variable, this paper analyzes the relationship in the exploratory community model. The results show that the overall Cronbach's $\alpha$ coefficient is 0.933 and the KMO value is 0.923 , indicating that the questionnaire designed has good reliability and validity. Teaching presence and social presence plays a significant positive role in cognitive presence. Self-efficacy plays a complete and partial mediating role in teaching presence and social presence and has a significant positive effect on cognitive presence. The results of this paper have important reference value for expanding the framework of an inquiry community, realizing the deep construction of learners' knowledge connotation, analyzing the influence mechanism of teachers and students in network teaching, and enriching the application of the inquiry community model.
\end{abstract}

Keywords—-self-efficacy, explore the community model, mediating effect

\section{Introduction}

Online learning has become another major channel for extensive offline learning because of its cross-time and convenient time. By accelerating the construction of the 5G and classroom revolution, China has gradually and comprehensively built a mainstream online teaching platform with MOOC and live courses in Chinese universities, which has become an important way for people to realize lifelong learning. In essence, online learning involves using the mobile Internet to acquire a variety of massive learning materials online and realize effective interaction with online learning participants, such as teachers and classmates to increase learners' knowledge content and build personal knowledge system. Compared with other learning methods, some 
online learning platforms also lack learners' sense of learning efficacy because of the lax control of learners' qualifications, the lack of supervision of the teaching process, the untimely interaction between teachers and students, and the unscientific assessment methods, which hinders the levels of teachers' teaching performance and students' learning performance from reaching a higher level. In the process of online learning, learners need to constantly adjust their self-learning state and improve their sense of learning self-efficacy to continuously promote endogenous learning motivation, stimulate their motivation and beliefs, and other individual subjective reasons. Schools should also increase the training of teachers' online education methods and provide a good platform for their online resource production, making teachers and students better participate in online learning.

In the online learning environment, the infrequent face-to-face interaction between teachers and students and the non-physical communication between students lead to learners' loneliness and anxiety. To ensure the longevity and continuity of online learning quality, learners must increase their learning input to achieve deeper and higher-order thinking learning. A large number of studies have shown that the online learning experience can be significantly improved by creating an online learning community. Inquiry into the community theory involves analyzing the three mutually influencing elements to promote a deeper and more meaningful learning process. The three presences proposed by the inquiry community theory have become the basic theories for analyzing online learning that is highly accepted globally. A theoretical framework has been proposed for learning participants (teachers, students) to achieve effective learning interaction and collaboration. By enhancing the learner's experience, teachers can create a learning atmosphere of mutual trust and good open communication between teachers and students by strengthening the targeted curriculum design of online learning and realize the effective collaborative development and cohesion enhancement of the online learning community. In particular, teachers should have plans for the design the course teaching plan, improve the teaching methods, optimize the distribution of learning time, effectively monitor the online learning process and timely feedback the learning quality, and other measures to achieve the good strategy of online teaching subjects. The students of online teaching objects should also adjust their self-learning behavior by fully understanding the learning objectives, adjusting learning strategies, improving their learning enthusiasm, and realizing effective self-evaluation to comprehensively improve the online learning performance level and achieve more learning achievements. Therefore, in the process of online learning, based on the theory of inquiry community, the interaction mechanism between teachers and students is analyzed, and students' self-efficacy can be included to measure the interaction of the three spots in the inquiry community model, which can provide decision-making reference for improving learners' online learning quality. 


\section{Theoretical basis and proposed hypotheses}

\subsection{Theoretical basis}

In 1999, Canadian scholar Garrison, D.R. proposed the theory of exploring the community based on an extensive summary of existing research. Its greatest contribution was to fully study this theory and make full use of it to study online learning [1]. This theory proposes the concepts of "three on-the-spot" and "three on-the-spot", which are used to analyze and explain how to complete effective knowledge construction in the online learning process, and comprehensively decompose the behavior and process of knowledge construction. The first is teaching presence, which refers to how schools and teachers realize the teaching organization and teaching design of online learning, comprehensively promote the communication between teachers and students, and make teachers' teaching guidance fully implemented. The focus of teaching practice is to focus on how teachers can create a rich teaching effect and teaching objectives and explore the specific things that the community should complete, as a whole, including curriculum objective design, learning process design, and time arrangement. At the same time, teachers organize, command, and supervise teaching activities, and promote students to strengthen cooperation and reflection. Through such scientific design of teaching activities, students can achieve efficient and interesting learning behavior. A large number of research literature also support the view that teaching presence can promote learners to accelerate the construction of knowledge and realize knowledge sharing, and strengthen learners' social presence and cognitive presence. The second is social presence. In online learning, by strengthening the emotional communication between students and promoting the interaction between teachers and students, the learners' online voice can be improved. The online platform creates a construction of mutual consultation and knowledge collaborative learning for learners. The environment is more conducive to cultivating learners' critical thinking and higher-level cognitive learning. The third presence is a cognitive presence, which reflects the extent to which learners in the online learning community have constructed knowledge through various interactive behaviors, and reflects the level of learning achievement of the learners. In the online learning process, taskdriven learning is completed by identifying questions and solving answers, motivating students to fully engage in learning, realizing exploratory learning of problems, integrating and analyzing the information of the exploratory process, formulating solutions, and finally realizing the solution. The inquiry community model provides unique perspectives, methods, and tools for online learning research, which has been widely recognized.

Bandura. proposed the concept of self-efficacy and conducted in-depth empirical research. Self-efficacy refers to an individual learner's self-subjective judgment on whether the self can achieve the goal [2], complete the task to achieve a certain achievement, and play a moderating role in the learning process. A large number of studies have shown that positive self-efficacy can achieve self-learning adjustment to a certain extent and stimulate endogenous learning motivation. With the gradual maturity of this theory, many scholars have conducted more research on the internal 
relationship between self-efficacy and other cognitive variables, such as the mechanism between mental model, learning performance, regulatory ability, and selfefficacy. Research results show that self-efficacy plays a complete or partial mediating effect in the community search model, which provides a research basis for this paper to put forward several research hypotheses.

\subsection{Hypothesis proposal}

Community theory framework, as an important theory in the field of distance education, has a great influence on online education teaching practice and research. A large number of research documents have verified the relationship between the community of inquiry framework and three kinds of telepresence. This paper also adopts more classic research questionnaires and research methods and believes that both teaching presence and social presence will have a very significant effect on cognitive presence and are important predictors.

Regarding the relationship between teaching presence and cognitive presence, Arbaugh analyzed the structural validity of teaching presence by using a sample of 191 MBA students to test the hypothetical model through the structural equation model and highlighted the potential for further research and application of the community inquiry model in online management education [3]. Shea reported a significant connection between students' sense of learning community and effective instructional design and the "directed promotion" of course teachers [4]. Gurley believed that teaching presence is the key to achieving students' learning outcomes [5]. The results show that teachers' teaching presence in the online learning environment has significant differences in promoting students' learning performance. Swan studied the effects of curriculum interface, teaching presence [6], and learner characteristics on students' learning in an asynchronous online curriculum environment. The results show that teaching presence has a very important effect on students' learning, and proposed the important relationship between them. Kupczynski used a mixed approach to explore the effects of teaching presence on students' performance [7]. Zhang conducted a questionnaire survey among 218 middle school English teachers who took part in online professional development courses [8]. The results showed that learners' perceived teaching existence had a positive effect on their constructive and interactive participation behavior. Dockter discussed the effect of teaching presence in online teaching, and the results showed that effective teaching presence in distance teaching can be a powerful factor to help online students succeed in the course [9]. Khalid conducted a questionnaire survey among several university of a Malaysian university and attended at least one mixed or completely online course [10]. Through Qualtrics online survey, the previous study showed that the results indicate a significant positive correlation between the two variables of teaching presence and students' curriculum satisfaction. Chakraborty emphasized the importance of teaching presence and teacher immediacy in the online classroom environment [11]. The research results show that teaching presence and teaching immediacy will affect learners' cognitive and emotional learning experience. Prasad showed that when increasing teaching 
participation in discussion forums [12], learners' critical thinking level will be significantly improved. Therefore, hypothesis $\mathrm{H} 1$ is proposed:

Hypothesis $\mathrm{H} 1$ : teaching presence has an obvious positive promoting effect on cognitive presence.

As to the relationship between social presence and cognitive presence, Aragon believed that social presence is one of the most important factors to improve teaching effect and establish community awareness, and discussed the strategies of creating a social presence in an online environment [13]. Tu studied the role of social presence in the online learning environment and found that the three dimensions of social presence, social background, online communication, and interactivity have become important factors in establishing community awareness among online learners [14]. Tu believed that social presence is an important social factor in distance education [15]. Social presence includes three dimensions: social context, online communication, interactivity, and privacy. Kehrwald derived the definition of social presence from the learner's experience, and explained the nature of social presence in the online learning environment [16]. Cobb discussed the relationship between social presence and student satisfaction and reported that online course students felt comfortable connecting and interacting in an online environment [17], and are satisfied with online courses. Cui analyzed the origin and main definition of social presence and provided instructional design suggestions for the development of online social presence [18]. Hostetter studied the relationship between social presence and student learning results and reported that students with higher social skills score statistically higher on CAT [19], indicating that social presence affected the results of students' written work. Kim indicated that media integration and teachers' teaching quality are significant predictors of social presence and learning satisfaction [20]. Lowenthal conducted a full study on the definition of social presence [21]. Richardson believed that social presence will affect students' motivation, participation [22], and actual learning satisfaction reported a moderate positive average correlation between social presence and satisfaction, social existence, and perceived learning. Therefore, this paper puts forward hypothesis $\mathrm{H} 2$.

Hypothesis H2: Social presence has an obvious positive promoting effect on cognitive presence.

A large number of studies have also shown that the interaction between teaching presence, social presence, and cognitive presence is also affected by the mediating effects of other variables. This article believes that self-efficacy will play such an intermediary role. Shea conducted a study on 3165 online courses and mixed courses and explored the moderating role of cognition [23], behavior, and motivation. Lin, (215) showed that self-efficacy is a positive influence of social presence on cognitive presence, which plays a complete mediating effect [24]. Shu reported that selfefficacy can promote learning performance in the virtual environment [25]. Park analyzed online learning presence, self-efficacy, and their relationship with academic achievement in online universities [26]. The results showed that self-efficacy played an intermediary role in promoting the academic achievement of students. Jia analyzed the influence of self-efficacy on the effectiveness of training systems in the virtual environment [27], and the results showed that self-efficacy had a significant positive 
influence on the effectiveness of the training system. Therefore, this paper puts forward the following assumptions:

Hypothesis H3: Self-efficacy plays an intermediary role in the positive promotion of teaching presence on cognitive presence.

Hypothesis H4: self-efficacy plays a mediating effect in the obvious positive promotion of social presence on cognitive presence.

\section{Research design}

\subsection{Survey design}

In this study, the questionnaire of "Self-efficacy and Exploring Community Model" was designed by the research group, and included 32 questions. The first part of the questionnaire pertains to the basic statistics of the respondents, including three items, namely, gender, grade, and major. The second part is a questionnaire with core variables. In terms of exploring communities, this article selects the Chinese version of the Inquiry Community Scale revised and compiled by Guoshuai [28] and others. This scale includes the teaching presence, social presence, and observational data in three aspects including cognitive presence. The scale partially modified the original English version of the Inquiry Community Scale, which is more in line with the online learning environment of China's informatization. The use of this scale will help improve the scientific nature of the research. According to the exploratory factor analysis conducted by Guoshuai, combined with the research needs, the principal component correspondence of each item, and the characteristics of online learning, this study adopted 21 items of the original scale. Among them, nine are teaching spots, six are cognitive spots, and six are social spots. Self-efficacy is defined as learning persistence and the ability to deal with failures and setbacks in the process of completing related learning tasks. It can be used as an important observation index that affects learners' on-the-spot performance. In this study, Pintrich's learning motivation strategy scale was selected, in which eight items measure learners' self-efficacy [29].

\subsection{Research sample}

This study is based on the self-developed online learning center of a 211 university in Jiangsu Province. The self-developed online learning platform of this university has passed the one-and-a-half-year operation in 2020 and the first half of 2021 [30]. On the whole, it provides students with an open and shared information-based online learning environment and online learning courses based on a net platform. Considering the particularity of online learning and that graduate students have a good theoretical foundation and are familiar with technology application, a questionnaire survey was conducted among the graduate students in the school of education. The objects of this survey are graduate students with a good information foundation, online course technology, and an online learning experience. They have good information technolo- 
gy literacy and can adapt to the online teaching and personalized learning modes in the information environment. The survey used an online questionnaire with a Likert 5-point scale, which was launched in the form of a QR generated by the China questionnaire star platform. Graduate students scanned the QR code to answer questions on site. A total of 312 questionnaires were recovered. After excluding the invalid questionnaires with a low completion rate, 243 valid questionnaires were recovered, and the effective recovery rate was $77.88 \%$.

Table 1. Descriptive statistics results

\begin{tabular}{|c|c|c|c|c|}
\hline Name & Option & Frequency & Percentage $(\%)$ & Cumulative percentage $(\%)$ \\
\hline \multirow{2}{*}{ Gender } & Man & 104 & 42.8 & 42.8 \\
\hline & Woman & 139 & 57.2 & 100 \\
\hline \multirow{3}{*}{$\begin{array}{l}\text { Graduate } \\
\text { grade }\end{array}$} & First year graduate student & 68 & 27.98 & 27.98 \\
\hline & Second year graduate student & 131 & 53.91 & 81.89 \\
\hline & Third year graduate student & 44 & 18.11 & 100 \\
\hline \multirow{9}{*}{ Major } & Foundations of education & 103 & 42.39 & 42.39 \\
\hline & History of education & 51 & 20.99 & 63.37 \\
\hline & Comparative education & 34 & 13.99 & 77.37 \\
\hline & Pre-school Education & 24 & 9.88 & 87.24 \\
\hline & Adult pedagogy & 20 & 8.23 & 95.47 \\
\hline & $\begin{array}{c}\text { Vocational and technical educa- } \\
\text { tion }\end{array}$ & 2 & 0.82 & 96.3 \\
\hline & $\begin{array}{c}\text { Education economy and man- } \\
\text { agement }\end{array}$ & 2 & 0.82 & 97.12 \\
\hline & Distance learning & 4 & 1.65 & 98.77 \\
\hline & Special pedagogy & 3 & 1.23 & 100 \\
\hline \multicolumn{2}{|l|}{ Total } & 243 & 100 & 100 \\
\hline
\end{tabular}

\section{$4 \quad$ Result analysis}

\subsection{Reliability and validity analysis}

Reliability refers to reliability, consistency, or stability. The results of multiple measurements are very close in the measurement of the same object. Generally, the result is considered credible and true, that is, the reliability is high. If the results of each measurement are very different, the reliability is low. In the same questionnaire research, reliability analysis is also used to measure whether the sample answer is true and reliable. The higher the test reliability, the more credible the result. Many methods have been used to measure reliability, among which the commonly used intrinsic reliability coefficients include Cronbach's $\alpha$ coefficient and half coefficient. In this paper, the commonly used Cronbach's $\alpha$ coefficient is adopted. Generally speaking, if the value of the alpha coefficient is higher than 0.8 , it means high reliability; If the value is between 0.7 and 0.8 , the reliability is good. If this value is between 0.6 and 0.7 , the reliability is acceptable. If this value is less than 0.6 , the reliability is poor. 
Table 2 shows the overall Cronbach $\alpha$ coefficient of this questionnaire is 0.933 , which is greater than 0.9 , indicating that the reliability of the research data is of high quality.

Table 2. Reliability test structure

\begin{tabular}{|c|c|c|c|c|c|}
\hline Variable & Question number & \begin{tabular}{|c|} 
Total correlation of \\
correction items(CITC)
\end{tabular} & $\begin{array}{l}\text { Deleted } \alpha \\
\text { coefficient }\end{array}$ & $\begin{array}{c}\text { Cronbach } \alpha \\
\text { coefficient }\end{array}$ & $\begin{array}{c}\text { Cronbach } \alpha \\
\text { coefficient }\end{array}$ \\
\hline \multirow{9}{*}{$\begin{array}{l}\text { Teaching } \\
\text { on the } \\
\text { spot } \\
\text { (TP) }\end{array}$} & TP1 & 0.419 & 0.806 & \multirow{9}{*}{0.814} & \multirow{29}{*}{0.933} \\
\hline & TP2 & 0.414 & 0.808 & & \\
\hline & TP3 & 0.486 & 0.799 & & \\
\hline & TP4 & 0.536 & 0.793 & & \\
\hline & TP5 & 0.490 & 0.799 & & \\
\hline & TP6 & 0.618 & 0.783 & & \\
\hline & TP7 & 0.645 & 0.779 & & \\
\hline & TP8 & 0.538 & 0.793 & & \\
\hline & ТP9 & 0.463 & 0.803 & & \\
\hline \multirow{6}{*}{$\begin{array}{l}\text { Social } \\
\text { presence } \\
(\mathrm{SP})\end{array}$} & SP1 & 0.47 & 0.697 & \multirow{6}{*}{0.734} & \\
\hline & SP2 & 0.463 & 0.699 & & \\
\hline & SP3 & 0.335 & 0.735 & & \\
\hline & SP4 & 0.435 & 0.708 & & \\
\hline & SP5 & 0.543 & 0.675 & & \\
\hline & SP6 & 0.587 & 0.664 & & \\
\hline \multirow{6}{*}{$\begin{array}{l}\text { Cognitive } \\
\text { presence } \\
\text { (CP) }\end{array}$} & CP1 & 0.48 & 0.787 & \multirow{6}{*}{0.8} & \\
\hline & CP2 & 0.491 & 0.785 & & \\
\hline & CP3 & 0.524 & 0.777 & & \\
\hline & $\mathrm{CP} 4$ & 0.57 & 0.766 & & \\
\hline & CP5 & 0.646 & 0.749 & & \\
\hline & CP6 & 0.634 & 0.751 & & \\
\hline \multirow{8}{*}{$\begin{array}{l}\text { Self- } \\
\text { efficacy } \\
\text { (SE) }\end{array}$} & SE1 & 0.49 & 0.852 & \multirow{8}{*}{0.857} & \\
\hline & SE2 & 0.608 & 0.839 & & \\
\hline & SE3 & 0.597 & 0.84 & & \\
\hline & SE4 & 0.642 & 0.834 & & \\
\hline & SE5 & 0.631 & 0.835 & & \\
\hline & SE6 & 0.677 & 0.83 & & \\
\hline & SE7 & 0.65 & 0.833 & & \\
\hline & SE8 & 0.502 & 0.85 & & \\
\hline
\end{tabular}

Validity analysis refers to the validity and accuracy of questionnaire design. When designing a questionnaire for the research topic, we all hope that the actual measurement of the problem is what we want to measure, so that the research data can accurately explain the problem. Generally speaking, when analyzing the KMO value, if the value is higher than 0.8 , it indicates that it is very suitable for information extraction. Meanwhile, if the value is between 0.7 and 0.8 , it indicates that it is more suitable for information extraction (from one side, it indicates that the validity is better). If 
this value is between 0.6 and 0.7 , it indicates that information extraction can be carried out (from one side, it indicates that the validity is general). If this value is less than 0.6, the information is difficult to extract.

Table 3 shows that that KMO and Bartlett tests are used for validity verification. The KMO value is 0.923 and the KMO value is greater than 0.8 , and thus, the research data is very suitable for extracting information.

Table 3. Inspection of KMO and Bartlett

\begin{tabular}{|l|c|c|}
\hline \multicolumn{2}{|l|}{ KMO value } & 0.923 \\
\hline \multirow{3}{*}{ Bartlett Sphericity Test } & Approximate chi-square & 3148.463 \\
\cline { 2 - 3 } & $\mathrm{df}$ & 406 \\
\cline { 2 - 3 } & P value & 0 \\
\hline
\end{tabular}

\subsection{Regression analysis}

Table 4 shows the following:

The regression coefficient value of teaching presence is $0.486 \quad(t=8.496$, $\mathrm{p}=0.000<0.01$, which means that teaching presence will have a significant positive effect on cognitive presence. Thus, hypothesis $\mathrm{H} 1$ is established, that is, teaching presence has an obvious positive promotion effect on cognitive presence. The main reason is that the design and organization of teaching on-site aims to give full play to the teacher's identity as the "designer" of student learning, that is, the teacher designs learning resources, learning activities, and curriculum arrangements before the start of the course. Instructional design and organization have a significant effect on cognitive presence, requiring teachers and students to interact to determine one or more questions for exploration. Good online learning course content, planning online course structure, process, and interaction, and designing online learning activities can ensure the smooth progress of students' cognitive activities. During the implementation of online courses, students learn to master new knowledge, find solutions to curriculum problems, apply new knowledge to solve problems related to courses and ensure that the new knowledge already built in the courses can solve problems. It is fully proved that a good teaching spot can promote students' cognitive activities to the solution stage, and a good route is designed for students' continuous inquiry, which makes the teaching spot have a significant impact on the cognitive spot solution stage.

The regression coefficient of social presence is $0.406(t=7.021, p=0.000<0.01)$, which means social presence has a significant positive influence on cognitive presence. Hypothesis $\mathrm{H} 2$ holds, that is, social presence has an obvious positive promoting effect on cognitive presence. Because online education fully realizes the knowledge sharing between students and teachers. In the process of online learning, social interaction needs to be completed by various social media. By strengthening interaction, the online learning community realizes timely and effective communication between students and teachers, establishes comprehensive trust, and displays personal real and effective information and teaching and learning achievements through the online 
learning platform, which can comprehensively improve the cognitive presence of graduate students.

Table 4. Regression results

\begin{tabular}{|l|c|c|c|}
\hline & Coefficient of regression & 95\% CI & VIF \\
\hline Constant & $0.449^{* *}(2.687)$ & $0.121 \sim 0.776$ & - \\
\hline Teaching on the spot & $0.486^{* *}(8.496)$ & $0.374 \sim 0.599$ & 2.041 \\
\hline Social presence & $0.406^{* *}(7.021)$ & $0.292 \sim 0.519$ & 2.041 \\
\hline Sample size & \multicolumn{3}{|c|}{0.637} \\
\hline $\mathrm{R}^{2}$ & \multicolumn{3}{|c|}{0.634} \\
\hline Adjust $\mathrm{R}^{2}$ & $\mathrm{~F}(2,240)=210.903, \mathrm{p}=0.000$ \\
\hline F value & \multicolumn{3}{|c|}{} \\
\hline
\end{tabular}

Dependent variable: cognitive presence

$\mathrm{D}-\mathrm{W}$ value: 1.965

${ }^{*} \mathrm{p}<0.05^{* *} \mathrm{p}<0.01 \mathrm{~T}$ value in parentheses

\subsection{Mediating effect analysis}

Table 5 shows that $\mathrm{H} 3$ and $\mathrm{H} 4$ are supported. Self-efficacy plays a complete mediating effect in the positive promotion of teaching presence on cognitive presence. In the process of online learning, learners' sense of self-efficacy can effectively connect teaching presence with understanding presence, accelerate various high-quality resources in the teaching process, realize the transformation of students' good knowledge system construction, help learners maintain a high learning state and effective learning investment, and realize the cultivation of learners' critical thinking and high-order thinking, It improves the learning quality of learners. When preparing online teaching resources, teachers, as teaching subjects, strengthen the teaching design of online courses by developing new autonomous learning methods suitable for graduate students, which makes teaching more colorful and ensures that students can effectively realize deep learning. Learners' self-efficacy can be maintained at a high level after being promoted, which can comprehensively enhance their cognitive existence.

Table 5. Mediation effect results

\begin{tabular}{|c|c|c|c|c|c|c|c|c|c|c|}
\hline $\begin{array}{l}\text { Influ- } \\
\text { ence } \\
\text { path }\end{array}$ & $\begin{array}{c}c \\
\text { Total } \\
\text { effect }\end{array}$ & $\mathbf{a}$ & b & \begin{tabular}{|c|}
$a^{*} \mathbf{b}$ \\
Mediating \\
effect value
\end{tabular} & $\begin{array}{l}\mathbf{a}^{*} \mathbf{b} \\
(\text { Boot } \\
\text { SE) }\end{array}$ & $\begin{array}{l}\mathbf{a}^{*} \mathbf{b}(Z \\
\text { value })\end{array}$ & $\begin{array}{l}\mathbf{a}^{*} \mathbf{b}(\mathbf{P} \\
\text { value })\end{array}$ & $\begin{array}{c}a^{*} \mathbf{b}(95 \% \\
\text { BootCI })\end{array}$ & $\begin{array}{c}\text { c' } \\
\text { Direct } \\
\text { effect }\end{array}$ & $\begin{array}{c}\text { Test } \\
\text { conclusion }\end{array}$ \\
\hline $\begin{array}{l}\mathrm{SP}=>\mathrm{SE} \\
=>\mathrm{CP}\end{array}$ & $0.382^{* *}$ & $0.307^{* *}$ & $0.265^{* *}$ & 0.082 & 0.002 & 48.275 & 0 & $\begin{array}{c}0.029 \sim \\
0.131\end{array}$ & $0.301^{* *}$ & $\begin{array}{c}\text { Partial } \\
\text { intermedi- } \\
\text { ary }\end{array}$ \\
\hline
\end{tabular}

Self-efficacy plays a part of the intermediary role in the positive promotion of social presence on cognitive presence. Self-efficacy can effectively promote students' active network inquiry learning and improve their cognitive level. In students' online learning, teachers are also fully involved in the learning process, recovering students' 
online learning questions, strengthening interaction with students, and making students fully feel the guidance and supervision of teachers on their learning process, which can comprehensively enhance the social presence effect. At the same time, by building an interactive platform that satisfies the comprehensive and effective communication between learners and between learners and teachers, scientific evaluation of the communication and feedback between them is realized, especially the maturity of educational information technology, which enables big data to be integrated into online learning. Techniques, such as academic analysis and data mining are used to comprehensively characterize learners' online learning interactions and visually present them to stimulate learners' sense of self-efficacy and allow them to maintain a high level of self-efficacy, and reach the construction of a knowledge system and complete the learning process of exploring knowledge.

\subsection{Variance test}

Table 6 shows that the samples of different grades have significant differences in the cognitive presence $(\mathrm{P}<0.05)$, which means the samples of different grades have differences in cognitive presence. The specific analysis shows that grade has a significance level of 0.05 for cognitive presence $(\mathrm{F}=3.893, \mathrm{P}=0.022)$, and the specific comparison difference indicates that the average score of the group with an obvious difference is that the cognitive presence of the third-year students is higher than that of the second and first-year students. The main reason is that the survey objects of this paper are graduate students majoring in pedagogy. After completing their undergraduate studies, the first-year graduate students focus mainly on theoretical learning, and their mastery of online learning technology is not as good as the third-year graduate students. After two years' training, the third-year graduate students' overall educational technology skills are relatively perfect, and their cognitive presence in online learning is significantly higher than that of the first- and second-grade students. However, the graduate students of different majors do not have significant differences in cognition. This conclusion is easy to accept mainly because the survey objects in this paper are all graduate students of related education majors and no obvious difference in their basic theories of education and educational teaching techniques can be found, which fully reflects the professional balance of the surveyed colleges in teaching the basic theories of graduate education. At the same time, it also inspires colleges to pay attention to broadening their majors in the teaching of basic theoretical knowledge and lay a solid foundation for students of different majors. 
Table 6. Results of variance test

\begin{tabular}{|c|c|c|c|c|c|c|c|c|c|c|c|}
\hline \multicolumn{10}{|c|}{ Grade (mean \pm standard deviation) } & $\mathbf{F}$ & $\mathbf{P}$ \\
\hline \multirow{5}{*}{$\begin{array}{l}\text { cognitive } \\
\text { presence }\end{array}$} & \multicolumn{3}{|c|}{$1.0(\mathrm{n}=68)$} & \multicolumn{3}{|c|}{$2.0(\mathrm{n}=131)$} & \multicolumn{3}{|c|}{$3.0(n=44)$} & & \\
\hline & \multicolumn{3}{|c|}{$3.70 \pm 0.63$} & \multicolumn{3}{|c|}{$3.86 \pm 0.54$} & \multicolumn{3}{|c|}{$4.01 \pm 0.60$} & 3.89 & $\begin{array}{c}0.02 \\
2^{*}\end{array}$ \\
\hline & \multicolumn{9}{|c|}{ Major (mean \pm standard deviation) } & \multirow[b]{2}{*}{$\mathrm{F}$} & \multirow[b]{2}{*}{$\mathrm{P}$} \\
\hline & $\begin{array}{c}1.0 \\
(n=103)\end{array}$ & $\begin{array}{c}2.0 \\
(n=51)\end{array}$ & $\begin{array}{c}3.0 \\
(n=34)\end{array}$ & $\begin{array}{c}4.0 \\
(n=24)\end{array}$ & $\begin{array}{c}5.0 \\
(n=20)\end{array}$ & $\begin{array}{c}6.0 \\
(n=2)\end{array}$ & $\begin{array}{c}7.0 \\
(n=2)\end{array}$ & $\begin{array}{c}8.0 \\
(n=4)\end{array}$ & $\begin{array}{c}9.0 \\
(n=3)\end{array}$ & & \\
\hline & $\begin{array}{c}3.90 \pm 0 \\
53\end{array}$ & $\begin{array}{c}3.77 \pm 0 . \\
60\end{array}$ & $\begin{array}{c}3.80 \pm 0 \\
73\end{array}$ & $\begin{array}{c}3.72 \pm 0 \\
59\end{array}$ & $\begin{array}{c}3.99 \pm 0 . \\
54\end{array}$ & $\begin{array}{c}4.08 \pm 0 . \\
35\end{array}$ & $\begin{array}{c}4.08 \pm 0 \\
12\end{array}$ & $\begin{array}{c}3.83 \pm 0 \\
83\end{array}$ & $\begin{array}{c}3.44 \pm 0 \\
.59\end{array}$ & $\begin{array}{c}0.79 \\
9\end{array}$ & $\begin{array}{c}0.60 \\
4\end{array}$ \\
\hline
\end{tabular}

\section{Conclusions}

The in-depth integration of mobile internet technology and education has enabled the vigorous development of online education at home and abroad and has promoted easier access to education across time and space for students. Based on the exploratory community model and self-efficacy theory, this paper establishes two models that affect cognitive presence in teaching presence and social presence and uses selfefficacy as an intermediary variable to analyze its relationship in the exploratory community model. The results show that the overall Cronbach's $\alpha$ coefficient and KMO value of this paper are 0.933 and 0.923 , respectively, thereby indicating that the questionnaire designed in this paper has good reliability and validity. Teaching presence and social presence will have obvious positive effects on cognitive presence. Self-efficacy played a complete mediating effect and a partial mediating effect in the obvious positive promoting effect of teaching presence and social presence on cognitive presence. Different grade samples have differences in cognitive presence. Thus, in the future, we can continue to conduct in-depth research on the role of self-efficacy under the mixed teaching mode in understanding the presence, optimizing digital teaching support services, deepening the improvement of learning performance brought by interactive learning, and understanding the role mechanism of artificial intelligence technology in the field of education in improving teaching and social existence.

\section{Acknowledgement}

The study was supported by the Research Project of Teaching Reform in Colleges and Universities of Hunan Province in 2020 (Project No. : HNJG-2020-1011). 


\section{$7 \quad$ References}

[1] Garrison, D.R., Anderson, T., Archer, W. Critical inquiry in a text-based environment: Computer conferencing in higher education. The internet and higher education, 1999, vol. 2(2), pp. 87-105. https://doi.org/10.1016/S1096-7516(00)00016-6

[2] Bandura, A. Reflections on self-efficacy. Advances in behaviour research and therapy, 1978, vol. 1(4), pp. 237-269. https://doi.org/10.1016/0146-6402(78)90012-7

[3] Arbaugh, J.B., Hwang, A. Does "teaching presence" exist in online MBA courses? The Internet and Higher Education, 2006, vol. 9(1), pp. 9-21. https://doi.org/10.1016/j.iheduc. 2005.12.001

[4] Shea, P., Li, C.S., Pickett, A. A study of teaching presence and student sense of learning community in fully online and web-enhanced college courses. The Internet and higher education, 2006, vol. 9(3), pp. 175-190. https://doi.org/10.1016/j.iheduc.2006.06.005

[5] Gurley, L.E. Educators' Preparation to Teach, Perceived Teaching Presence, and Perceived Teaching Presence Behaviors in Blended and Online Learning Environments. Online learning, 2018, vol. 22(2), pp. 197-220. https://doi.org/10.24059/olj.v22i2.1255

[6] Swan, K. Learning online: A review of current research on issues of interface, teaching presence and learner characteristics. Elements of quality online education: Into the mainstream, 2004, vol. 5, pp. 63-79.

[7] Kupczynski, L., Ice, P., Wiesenmayer, R., McCluskey, F. Student perceptions of the relationship between indicators of teaching presence and success in online courses. Journal of Interactive Online Learning, 2010, vol. 9(1). pp. 23-43.

[8] Zhang, H., Lin, L., Zhan, Y., Ren, Y. The impact of teaching presence on online engagement behaviors. Journal of educational computing research, 2016, vol. 54(7), pp. 887-900. https://doi.org/10.1177/0735633116648171

[9] Dockter, J. The problem of teaching presence in transactional theories of distance education. Computers and Composition, 2016, vol. 40, pp. 73-86. https://doi.org/10.1016/ j.compcom.2016.03.009

[10] Khalid, M.N., Quick, D. Teaching Presence Influencing Online Students' Course Satisfaction at an Institution of Higher Education. International Education Studies, 2016, vol. 9(3), pp. 62-70. https://doi.org/10.5539/ies.v9n3p62

[11] Chakraborty, M., Nafukho, F. M. Strategies for Virtual Learning Environments: Focusing on Teaching Presence and Teaching Immediacy. Internet Learning Journal, 2015, vol. 4(1). pp. 8-37. https://doi.org/10.18278/i1.4.1.1

[12] Prasad, D. Empirical study of teaching presence and critical thinking in asynchronous discussion forums. International Journal of Instructional Technology and Distance Learning, 2009, vol. 6(11), pp. 3-26.

[13] Aragon, S.R. Creating social presence in online environments. New directions for adult and continuing education, 2003, vol. 2003(100), pp. 57-68. https://doi.org/10.1002/ace.119

[14] Tu, C.=H., McIsaac, M. The relationship of social presence and interaction in online classes. The American journal of distance education, 2002, vol. 16(3), pp. 131-150. https://doi. org/10.1207/S15389286AJDE1603_2

[15] Tu, C.H. The measurement of social presence in an online learning environment. International Journal on E-learning, 2002, vol. 1(2), pp. 34-45. https://doi.org/10.1080/0952398 $\underline{0010021235}$

[16] Kehrwald, B. Understanding social presence in text - based online learning environments. Distance Education, 2008, vol. 29(1), pp. 89-106. https://doi.org/10.1080/0158791080 2004860 
[17] Cobb, S.C. Social presence and online learning: A current view from a research perspective. Journal of Interactive Online Learning, 2009, vol. 8(3). pp. 241-254.

[18] Cui, G., Lockee, B., Meng, C. Building modern online social presence: A review of social presence theory and its instructional design implications for future trends. Education and information technologies, 2013, vol. 18(4), pp. 661-685. https://doi.org/10.1007/s10639012-9192-1

[19] Hostetter, C. Community matters: Social presence and learning outcomes. Journal of the Scholarship of Teaching and Learning, 2013, vol. 13(1), pp. 77-86.

[20] Kim, J., Kwon, Y., Cho, D. Investigating factors that influence social presence and learning outcomes in distance higher education. Computers \& Education, 2011, vol. 57(2), pp. 1512-1520. https://doi.org/10.1016/j.compedu.2011.02.005

[21] Lowenthal, P.R., Snelson, C. In search of a better understanding of social presence: An investigation into how researchers define social presence. Distance Education, 2017, vol. 38(2), pp. 141-159. https://doi.org/10.1080/01587919.2017.1324727

[22] Richardson, J.C., Maeda, Y., Lv, J., Caskurlu, S. Social presence in relation to students' satisfaction and learning in the online environment: A meta-analysis. Computers in Human Behavior, 2017, vol. 71, pp. 402-417. https://doi.org/10.1016/j.chb.2017.02.001

[23] Shea, P., Bidjerano, T. Learning presence: Towards a theory of self-efficacy, selfregulation, and the development of a communities of inquiry in online and blended learning environments. Computers \& education, 2010, vol. 55(4), pp. 1721-1731. https://doi. org/10.1016/j.compedu.2010.07.017

[24] Lin, S., Hung, T.C., Lee, C.T. Revalidate forms of presence in training effectiveness: Mediating effect of self-efficacy. Journal of Educational Computing Research, 2015, vol. 53(1), pp. 32-54. https://doi.org/10.1177/0735633115588772

[25] Shu, Y., Huang, Y.Z., Chang, S.H., Chen, M.Y. Do virtual reality head-mounted displays make a difference? A comparison of presence and self-efficacy between head-mounted displays and desktop computer-facilitated virtual environments. Virtual Reality, 2019, vol. 23(4), pp. 437-446. https://doi.org/10.1007/s10055-018-0376-x

[26] Park, S.Y., Woo, N.M. E-learning presence and self-efficacy and their relationships with learning achievement in cyber and consortium university. Journal of Agricultural Education \& Human Resource Development, 2014, vol. 44(1), pp. 109-129. https://doi. org/10.23840/agehrd.2012.44.1.109

[27] Jia, D., Bhatti, A., Nahavandi, S. The impact of self-efficacy and perceived system efficacy on effectiveness of virtual training systems. Behaviour \& Information Technology, 2014, vol. 33(1), pp. 16-35. https://doi.org/10.1080/0144929X.2012.681067

[28] Guoshuai, L., Qiuju, Z., Caijie, L.V., Yating, S., Jiacai, W. Construction of a chinese version of the community of inquiry measurement instrument. Open Education Research. 2018, vol. 24(3), pp. 68-76.

[29] Pintrich, P.R., Smith, D.A., Garcia, T., McKeachie, W.J. Reliability and predictive validity of the Motivated Strategies for Learning Questionnaire. Educational and psychological measurement, 1993, vol. 53(3), pp. 801-813. https://doi.org/10.1177/001316449305300 $\underline{3024}$

[30] Barnard, L., Lan, W.Y., To, Y.M., Paton, V.O., Lai, S.L. Measuring self-regulation in online and blended learning environments. The internet and higher education, 2009, vol. 12(1), pp. 1-6. https://doi.org/10.1016/j.iheduc.2008.10.005 
Paper-Research on the Relationship between Self-efficacy and Inquiry Community Model

\section{Author}

Xiang Zhou is a Lecturer in School of Foreign Languages, Hunan International Economics University, Changsha, Hunan 410205, China.

Article submitted 2021-10-01. Resubmitted 2021-12-03. Final acceptance 2021-12-06. Final version published as submitted by the author. 